\title{
DETERMINATION OF ORGANOCHLORINE PESTICIDE RESIDUES IN SOME VEGETABLES AND FRUIT BY QUEChERS TECHNIQUES AND GAS CHROMATOGRAPHY /MASS SPECTROMETRY
}

\author{
${ }^{* 1}$ Suleiman, F., ${ }^{2}$ Nuhu, A. A., ${ }^{2}$ Omoniyi, K. I. and ${ }^{2}$ Yashim, Z. I. \\ ${ }^{1}$ Department of Chemistry, Federal College of Education, Kontagora, Niger, Nigeria \\ ${ }^{2}$ Department of Chemistry, Ahmadu Bello University, Zaria, Kaduna, Nigeria \\ *Corresponding authors email: sulfanik2005@gmail.com
}

\begin{abstract}
The concentrations of organochlorine pesticide residues were analysed in some vegetables and fruit (spinach, lettuce, cabbage, tomatoes, carrots and onions) grown at Dagachi farming areas along River Galma of Zaria in Kaduna State, Nigeria. Sample collection and preparation were carried out using standard procedures. The concentrations of all the pesticides in the fruits and vegetables samples were analysed using quick easy cheap effective rugged and safe (QuEChERS) multi- residue extraction and clean up techniques, followed by gas chromatography - mass spectrometry (GC - MS). The most commonly detected organochlorine pesticide residues in the entire samples analysed are lindane, delta - BHC, heptachlor epoxide (B), endosulfan I, dieldrin, and endosulfan II. Furthermore, the results of the study shows that the mean concentration of these organochlorines pesticide detected were higher in onion and spinach with heptachlor epoxide (B) having concentrations $2.303 \mathrm{mg} / \mathrm{kg}$ and $2.011 \mathrm{mg} / \mathrm{kg}$ respectively. Likewise, endosulfan II (1.433 mg/kg) in lettuce was observed. Heptachlor epoxide (B) detected were also very high in other samples such as carrot, cabbage, and tomatoes and with values $0.600 \mathrm{mg} / \mathrm{kg}, 0.716$ $\mathrm{mg} / \mathrm{kg}$, and $0.524 \mathrm{mg} / \mathrm{kg}$ respectively. Indeed, these concentrations of all the organochlorine pesticides detected in the fruit and vegetables samples analysed were observed to be at alarming levels, much higher than the maximum residue limits (MRLs) by the Codex 2009 (WHO and FAO) except for lindane with values $0.007 \mathrm{mg} / \mathrm{kg}$ and $0.01 \mathrm{mg} / \mathrm{kg}$ in carrot and onions respectively lower than the MRLs. Dieldrin was only detected in carrot with a value of $0.008 \mathrm{mg} / \mathrm{kg}$. The occurrence of pesticides residues in the analysed samples is a major threat to human health. Hence, continuous monitoring is recommended so as to regulate the use of these pesticides in the study area.
\end{abstract}

Keywords: organochlorines, pesticide, pesticide residues, vegetables, fruits, and GC-MS

\section{INTRODUCTION}

Pesticides are widely used in agriculture to increase the yield, improve the quality, and extend the storage life of food crops (Fernandea-Alba and Garcia-Reyes, 2008). Pesticides are also used worldwide to protect crops before and after harvest in agriculture. Varieties of pesticides are used in current agricultural practice to manage pests and infections that spoil crops (Conacher and Mes, 1993). The controlled pesticides uses in agriculture will not affect the environment whereas uncontrolled pesticide use will cause adverse impacts on the environment such as water, soil and air which cause unbalance in ecosystem. Generally, a pesticide is a substance or a mixture of substances used for killing pests, organism dangerous to cultivated plants or to animals (USEPA, 2007). The term applies to various pesticides such as insecticide (for insects), fungicide (for fungi), herbicides (for weeds) and nematodes (for worm) (USEPA, 2007). Application of pesticides to crops may leave residues in or on food which are considered to be of toxicological significance.

Pesticide residue refers to the pesticides that remain on or in food after they are applied to food crops (Walter, 2009). The maximum allowable levels of these residues in foods are often stipulated by regulatory bodies in many countries. Many of these chemical residues, especially derivatives of chlorinated pesticides, exhibit bioaccumulation which could build-up to harmful levels in the body of organisms as well as in the environment (Walter, 2009). Persistent chemicals can be magnified through the food chain and have been detected in products ranging from meat, poultry and fish to vegetables oils, nuts, and various fruits and vegetables (Stephen and Benedict, 2011).

Some of these pesticides used in Nigeria have, for environmental reasons, been partially or completely banned in developed countries and even by National Agency For Food and Drug Administration and Control (NAFDAC) but for which effective and cheaper substitutes have yet to be evolved. Such pesticides continue to find their way into the Nigerian market for disease and pest control. According to Damala et al. (2011), pesticides use is known to cause serious environmental and health problems, especially in the dry season, during which the dilution capacity of the water systems is low, thus increasing the risk of high concentration of toxic pesticides. Pesticides have been associated with wide variety of human health hazards, ranging from acute impacts such as headache, vomiting, and diarrhoea to chronic impacts like cancer, reproductive harm, and endocrine disruption. Many people die from pesticides poisoning and other people suffer from various health effects (Akerblom, 1995).

Agricultural sector is the backbone of any growing economy worldwide. Export of these agricultural products such as vegetables and fruits are an important source of making foreign exchange for a country. Fruits and vegetables contain the essential elements of human diet. They are used to accomplish the requirements of balanced diet. They contain different nutritional elements such as different vitamins, minerals and 
antioxidant. Pesticides are used to increase the yield of agricultural products.

Zaria, in Kaduna State,Nigeria is a fruit and vegetable growing area in Northern Nigeria and literature surveys indicated that no study had been conducted on pesticide residues in fruits and vegetables in Dagachi farming area of Zaria in Kaduna state. Therefore, assessing the risk of pesticide residues in these commodities intended for human consumption is necessary. Because of their importance in terms of consumer safety, pesticide residues have been determined using methods based on gas chromatography- mass spectrometry (GC - MS) (Lehotay, et al., 2007). In the present work, Quick, Easy, Cheap, Effective, Rugged and Safe (QuEChERS) method and chromatographic techniques was used to identify and quantify selected organochlorine pesticide residues in vegetable and fruits samples produced along River Galma at Dagachi area of Zaria in Kaduna State, Nigeria.

\section{MATERIALS AND METHODS}

Analytical reagent grade (Analar) chemicals and distilled water was used throughout the work. All glassware and plastic containers was washed with detergent, $10 \%$ nitric acid and then rinsed with tap water and finally with distil water then allowed to dry.
Chemicals/Reagents

Certified reference standards of all the tested pesticides of $98 \%$ purity obtained from restek,

UK, Ltd was used. Ethyl acetate (99.5\%), Acetonitrile (99.9\%), Methanol (85\%), Distilled water, Primary secondary amine (PSA, $40 \mathrm{~cm}$ ) (Bondesil) sorbent (99.9\%), Anhydrous sodium sulphate $(90 \%)$, Magnesium sulphate $(88 \%)$, Hexane (99\%), Sodium chloride (90\%), Acetic acid (99.9\%), and Sodium acetate $(85 \%)$.

\section{Apparatus}

GC/MS QP2010 SHIMADZU, UK, Centrifuge machine, Blender, Microcentrifuge, Centrifuge tubes, Volumetric flash, Measuring cylinders, Beakers, Micro pipette or Automatic pipettes, Injection vials, $1,5 \mathrm{ml}$ suitable for GC and LC autosampler, Powered funnel to fill to the openings of the centrifuge tubes, polytetrafluroethylene (PTFE) screw cap, Vortex mixer.

\section{Sampling}

Samples was taken at five (5) random points (quadrant approach) at each farm land and mixed to constitute a composite of $1 \mathrm{~kg}$ in plastic bags and immediately transported to the laboratory and kept refrigerated before analysis. The map of the sampling site along River Galma is shown below

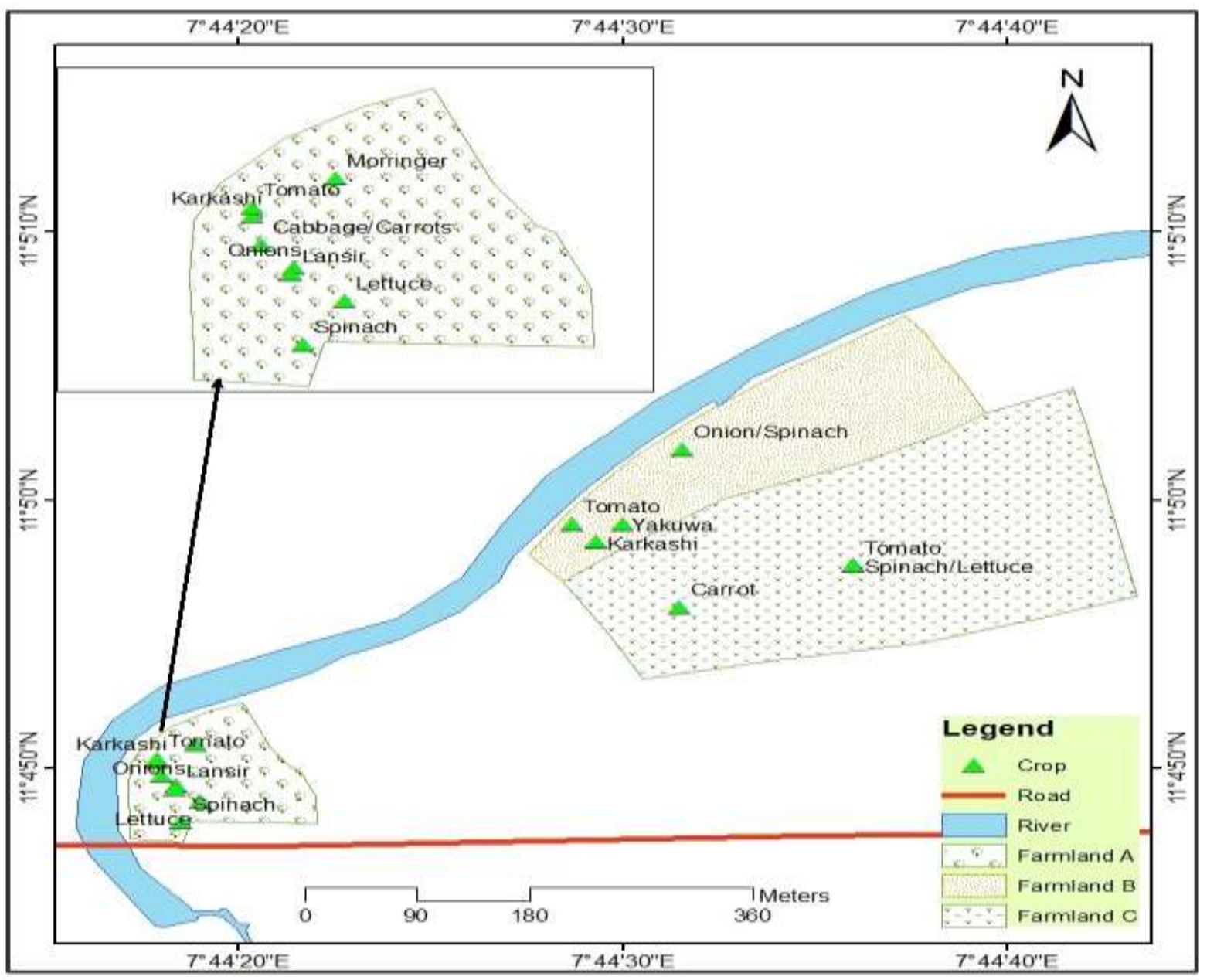

Figure 1: MAP OF THE SAMPLING AREA

\section{Sample Collection}

Samples of vegetables and fruit (spinach, onions, lettuce, tomatoes, cabbage and carrots) was collected from farm areas along River Galma in Zaria in plastic bags and kept refrigerated before analysis. Thereafter, the fresh samples were made into small pieces and homogenised with a household mill equipped with stainless steel knives, and finely ground in a high speed blender.

\section{Steps Involved in QuEChERS Technique}

Step 1: Sample Preparation and Extraction. Commodities are uniformly homogenised. Acetonitrile solvent is added for a shake extraction. 
Step 2: Extract Cleanup. A subsample of solvent extract is cleaned up using dSPE, a key improvement incorporated in the QuEChERS technique. Small polypropylene centrifuge tubes are prefilled with precise weights of $\mathrm{MgSO}_{4}$ and solid phase extraction (SPE) adsorbents to remove excess water and unwanted contaminants from the extracted samples.

Step 3: Sample Analysis. GC-MS

Preparation of Standard Solution / Calibration curves

Stock solutions were prepared containing $1000 \mathrm{mgdm}^{-3}$ of each compound to be investigated by accurately weighing 10 $\mathrm{mg}( \pm 0.01 \mathrm{mg})$ of each analyte in volumetric flasks and dissolving in $10 \mathrm{~cm}^{3}$ of methanol or acetonitrile contained in a beaker. These would be stored in dark vials in a refrigerator at $4^{0} \mathrm{C}$. Working standards were also prepared by serial dilutions. Final concentration (in acetonitrile) of $0.05,0.1,0.25,0.5$, and $1.0 \mathrm{mg} \mathrm{dm}^{-3}$ for each analyte was prepared. Standard solutions of the pesticides were run on GC/MS under the set chromatographic conditions and mean peak areas were plotted against concentrations to obtain calibration curves of individual pesticides. The calibration parameter is presented in Table 1

Table 1: Calibration parameters of the detected pesticides

\begin{tabular}{lccc}
\hline Pesticides & Linear range $(\mathrm{ppm})$ & Equation & Correlation Coefficient $\left(\mathrm{R}^{2}\right)$ \\
\hline Alpha - BHC & $0.05-1.00$ & $\mathrm{y}=6.859 \mathrm{x}-0.046$ & 0.999 \\
Lindane & $0.05-1.00$ & $\mathrm{y}=8.736 \mathrm{x}-0.039$ & 0.998 \\
delta - BHC & $0.05-1.00$ & $\mathrm{y}=4.102 \mathrm{x}-0.119$ & 0.999 \\
Hepta. Epoxide B & $0.05-1.00$ & $\mathrm{y}=3.084 \mathrm{x}+0.027$ & 0.999 \\
Endosulfan I & $0.05-1.00$ & $\mathrm{y}=1.638 \mathrm{x}-0.030$ & 0.998 \\
Endosulfan II & $0.05-1.00$ & $\mathrm{y}=3.343 \mathrm{x}-0.010$ & 0.998 \\
Dieldrin & $0.05-1.00$ & $\mathrm{y}=5.998 \mathrm{x}+0.040$ & 0.999 \\
\hline
\end{tabular}

\section{Extraction and Clean-up of Samples}

Homogenized samples $(15 \mathrm{~g})$ were weighted into a $50 \mathrm{~cm}^{3}$ polytetrafluro ethylene (PTFE) tube and $15 \mathrm{~cm}^{3}$ of acetonitrile containing $1 \%$ acetic acid (v/v) was added. Then $6 \mathrm{~g} \mathrm{MgSO}_{4}$ and $2.5 \mathrm{~g}$ of sodium acetate trihydrate (equivalent to $1.5 \mathrm{~g}$ of anhydrous form) was added and the sample shaken thoroughly for $4 \mathrm{~min}$ and kept in ice bath. The samples were then centrifuged at $4000 \mathrm{rpm}$ for $5 \mathrm{~min}$ and $6 \mathrm{~cm}^{3}$ of the supernatant transferred to a $15 \mathrm{~cm}^{3}$ PTFE tube to which $900 \mathrm{mg} \mathrm{MgSO}_{4}$ and $300 \mathrm{mg}$ PSA was added. The extract was shaken using a vortex mixer for $20 \mathrm{~s}$ and centrifuged at $4000 \mathrm{rpm}$ again for 5 min and $2 \mathrm{~cm}^{3}$ of the supernatant was taken in a vial. Then, it was further evaporated to dryness under a stream of nitrogen and reconstituted in $20 \mathrm{~cm}^{3} \mathrm{n}$-hexane in auto sampler tube for the GC - MS/Analysis. (AOAC, Official Method 2007.01).

Gas - Chromatography - Mass Spectrometry Analysis of The Samples

The samples (vegetables, fruits, water and soils) were analysed using the Shimadzu QP 2010 GC/MS equipped with chemstation software (GC 2071, Rev, A. 06.01). The primary capillary column for separation of pesticides was RTX-5 (Restek, $30 \mathrm{~m} \times 250 \mu \mathrm{m} \times 0.25 \mu \mathrm{m})($ Dem et al., 2007). The carrier gas was helium, with a constant column flow rate of 1.1 $\mathrm{ml} / \mathrm{min}$ and the detector make up gas was nitrogen at a flow rate of $60 \mathrm{ml} / \mathrm{min}$. The samples were injected in the splittless mode with the purge flow rate to split vent set at $35 \mathrm{ml} / \mathrm{min}$ at $1 \mathrm{~min}$ and pressure at $15 \mathrm{psi}$ and total flow at $39 \mathrm{ml} / \mathrm{min}$. The injector temperature $250{ }^{\circ} \mathrm{C}$ ( $\mathrm{RTX}-5$ injections) and the detector temperature programs was $350^{\circ} \mathrm{C}$. The temperature program on the TRX -5 capillary columns are as follows: $90^{\circ}$ $\mathrm{C}$ for $0.00 \mathrm{~min}, 30{ }^{\circ} \mathrm{C} / \mathrm{min}$ to $190{ }^{\circ} \mathrm{C}$ held for $20 \mathrm{~min}, 20{ }^{\circ} \mathrm{C}$ $/ \mathrm{min}$ to $275^{0} \mathrm{C}$ held for $10 \mathrm{~min}$. For confirmation runs, the temperature program on the RTX -35 columns are as follows: $100{ }^{0} \mathrm{C}$ for $2.0 \mathrm{~min}, 15^{\circ} \mathrm{C} / \mathrm{min}$ to $160^{\circ} \mathrm{C}, 5^{\circ} \mathrm{C} / \mathrm{min}$ to $270^{0}$ $\mathrm{C}$ held for $5 \mathrm{~min}$.

\section{RESULTS}

The identification of the compound was accomplished by comparing the retention times and mass spectra of analytes in samples to those of reference standards run at the same condition with the samples. Likewise, the concentrations of the pesticides were determined by intrapolation of the relative peak areas for each pesticide compared with those of the standard peak. Table 2 presents the validated parameter of the organochlorines while Table 3 shows the detected pesticide organochlorine pesticide residues in fruits and vegetables with their mean concentrations.

Table 2: Parameters For Validation of Organochlorines Pesticide.

\begin{tabular}{lllll}
\hline Pesticide & Linear range & $\mathrm{R}^{2}$ & LOD $(\mathrm{ppm})$ & $\mathrm{LOQ}(\mathrm{ppm})$ \\
\hline alpha- BHC & $0.05-1.00$ & 0.999 & 0.020 & 0.071 \\
Lindane & $0.05-1.00$ & 0.998 & 0.016 & 0.056 \\
delta- BHC & $0.05-1.00$ & 0.999 & 0.036 & 0.119 \\
Aldrin & $0.05-1.00$ & 0.999 & 0.031 & 0.104 \\
Heptachlor & $0.05-1.00$ & 0.999 & 0.048 & 0.158 \\
epoxide (B) & & & & \\
Endosulfan I & $0.05-1.00$ & 0.998 & 0.020 & 0.066 \\
Dieldrin & $0.05-1.00$ & 0.999 & 0.025 & 0.082 \\
Endosulfan II & $0.05-1.00$ & 0.998 & 0.010 & 0.030 \\
\hline
\end{tabular}

LOD - Limit of Detection $=3 \mathrm{~S}_{\mathrm{a}} / \mathrm{b}$

LOQ - Limit of Quantification $=10 \mathrm{~S}_{\mathrm{a}} / \mathrm{b}$

$\mathrm{R}^{2}$ - Correlation Coefficient

$\mathrm{S}_{\mathrm{a}}=$ standard deviation of the response (which is estimated as the standard deviation of $y$-intercept of the least square regression line, $\mathrm{R}^{2}$ ) (Garyd, 2008) and

$\mathrm{b}=$ slope of the calibration curve. 
Table 3: Mean Concentration (mg/kg) of Organochlorine Pesticide Residues in the Fruits and Vegetables at Dagachi Farm along River Galma.

S/n Samples alpha BHC lindane delta-BHC aldrin hept.epoxide B endosulfan I dieldrin endosulfan II

\begin{tabular}{lllccccccc}
\hline 1 & Spinach & ND & ND & $0.059 * \pm 0.050$ & ND & $2.011^{*} \pm 0.001$ & $0.038 \pm 0.017$ & ND & $0.090 * \pm 0.050$ \\
2 & Carrot & ND & $0.007 \pm 0.001$ & $0.030 \pm 0.001$ & ND & $0.600^{*} \pm 0.001$ & $0.080^{*} \pm 0.02$ & $0.008 \pm 0.001$ & $0.271 * \pm 0.01$ \\
3 & Onions & ND & $0.010 \pm 0.001$ & $0.122 * \pm 0.010$ & ND & $2.303 * \pm 0.001$ & $0.042 \pm 0.001$ & ND & $0.153 \pm 0.012$ \\
4 & Lettuce & ND & ND & $0.087 * \pm 0.030$ & ND & ND & $0.040 \pm 0.030$ & ND & $1.433 \pm 0.001$ \\
5 & Tomatoes & ND & ND & $0.058 * \pm 0.036$ & ND & $0.524 * 0.264$ & $0.048 \pm 0.037$ & ND & $0.068 \pm 0.016$ \\
6 & Cabbage & ND & ND & $0.111 \pm 0.004$ & ND & $0.716^{*} \pm 0.280$ & $0.059 \pm 0.001$ & ND & $1.058^{*} \pm 1.039$ \\
\hline
\end{tabular}




\section{DISCUSSION}

This study shows the evidence of the presence of pesticide residues in fruits and vegetable in Dagachi. The detected organochlorines pesticide residues in the spinach samples from the study area with their concentration are; delta- BHC $(0.059 \mathrm{mg} / \mathrm{kg})$, Heptachlor epoxide B $(2.011 \mathrm{mg} / \mathrm{kg})$, Endosulfan I $(0.038 \mathrm{mg} / \mathrm{kg})$, and Endosulfan II $(0.090 \mathrm{mg} / \mathrm{kg}$ ). The concentrations of the detected OCs were greater than Codex (FAO/WHO), 2006 recommended MRLS of 0.01 to $0.2 \mathrm{mg} / \mathrm{kg}$ of organochlorine residues in vegetable and fruits. Also, when compared to the work of Joseph et al. (2014), where they determined the organochlorines levels in five vegetable (spinach, lettuce, cabbage, tomato and onions) in Ghana are higher. In their work concentrations ranged from $0.225 \mathrm{mg} / \mathrm{kg}$ to $1.32 \mathrm{mg} / \mathrm{kg}$ with highest concentration of Dieldrin $(1.32 \mathrm{mg} / \mathrm{kg})$. Generally, the OCs are persistent pesticides which do not degrade easily in the environments therefore, the residual OCs in vegetables when consumed by man and animals has far reaching negative health implications such as tumors, heart diseases, infertility, skin alterations, nausea, neurological disorders, and kidney related diseases (Jobling et al., 1995).

Also, the following pesticide residues were detected in carrots; lindane, delta- BHC, heptachlor epoxide (B), endosulfan I , dieldrin and endosulfan II with their mean concentrations, $0.007 \mathrm{mg} / \mathrm{kg}, 0.030 \mathrm{mg} / \mathrm{kg}, 0.600 \mathrm{mg} / \mathrm{kg}$, $0.080 \mathrm{mg} / \mathrm{kg}, 0.008 \mathrm{mg} / \mathrm{kg}$, and $0.271 \mathrm{mg} / \mathrm{kg}$ respectively. In this study, it shows that delta - BHC, endosulfan I, heptachlor $\mathrm{B}$ and Endosulfan (II) have their concentrations above the Codex MRL, while others were lower. The results of the study were lower than those found in vegetable from three major markets in Ghana by Amoah et al. (2006) which exceeded the MRLs for consumption. Also, Adeyeye (1995) found that residue levels of OC pesticides in raw fruits in his work were generally low when compared with the FAOs maximum residue limits. In the work of Obonnaya (2017), the endosulofans were found to be $0.033 \mathrm{mg} / \mathrm{kg}$ which was also significantly higher than the recommended values by Codex Alimentarius. Indeed, endosulfan is carcinogenic, and causes infertility, neurological disorders and greatly worsens human and animal health problem (Sesling and Jackson, 1994).

Likewise, the following OCs pesticides were detected in onion samples analysed with their concentrations; lindane $(0.01 \mathrm{mg} / \mathrm{kg})$, delta $-\mathrm{BHC}(0.122 \mathrm{mg} / \mathrm{kg})$, heptachlor epoxide (B) $(2.303 \mathrm{mg} / \mathrm{kg})$, endosulfan I $(0.042 \mathrm{mg} / \mathrm{kg})$ and endosulfan II $(0.153 \mathrm{mg} / \mathrm{kg})$. The result shows that all the detected organochlorines have their concentrations above the recommended Codex Alimentanious MRLs, except for lindane. This shows that Good Agricultural Practice (GAP) was not strictly followed and also the farmers use these pesticides a lot in this area. The concentrations of organochlorines detected in this work were higher compared to those of similar works done elsewhere in Ghana. For example, Afful et al. (2008) reported levels of organochlorine residues in onions in Densu basin as ranging from 0.003 to $0.713 \mathrm{mg} / \mathrm{kg}$. Well, the higher level of the organochlorines in our work could be due misuse of these pesticides in the study area. Also, Lindane which marketed as Gammalin 20 and used by some farmers for crop protection in Nigeria should be discouraged.

The detected OCs in the lettuce are; delta - BHC (0.087 $\mathrm{mg} / \mathrm{kg})$, Endosulfan I $(0.040 \mathrm{mg} / \mathrm{kg})$, and Endosulfan II $(1.433 \mathrm{mg} / \mathrm{kg})$. The detected organochlorines were all above the recommended CodexMRLs, which shows that the usage of these pesticides in the study area is very high (Fan and Alexeeff, 1999). In the work of Ogbonnaya (2017), the values obtained for organochlorine in lettuce was between 0.023 $\mathrm{mg} / \mathrm{kg}$ to $0.078 \mathrm{mg} / \mathrm{kg}$, also higher than the MRLs WHO/FAO recommended values. The high values were attributed to the fact that the pesticides are not susceptible to volatization and photodegradation to form metabolities of these organochlorines.

The detected organochlorines in tomatoes are namely; deltaBHC $(0.058 \mathrm{mg} / \mathrm{kg})$, heptachlor epoxide $\mathrm{B}(0.524 \mathrm{mg} / \mathrm{kg})$, endosulfan I ( $0.048 \mathrm{mg} / \mathrm{kg})$ and endosulfan II $(0.068 \mathrm{mg} / \mathrm{kg})$. All the detected OCs have their concentrations above the recommended maximum residue limits by Codex Aliminetarius (2009). In their work, the concentration for all the organochlorines analysed ranged from $0.042 \mathrm{mg} / \mathrm{kg}$ to $6.915 \mathrm{mg} / \mathrm{kg}$ in Delta - HCH. Also, elsewhere in Ghana, Essumang et al. (2008) reported the concentrations of insecticides in tomatoes from Ghana ranged between 0.03 to $10.76 \mathrm{mg} / \mathrm{kg}$, which were slightly higher than the results in our study. Afful et al. (2010) also reported levels of organochlorines residues in tomatoes at Densu basin from 0.3 to to $1.3 \mu \mathrm{g} / \mathrm{kg}$. The presence of these organochlorines in tomato at our study area at appreciable levels is worrisome, since the detected pesticides are among the as persistent organic pollutants. The International Agency for Research on Cancer (IARC) has classified HCH (all isomers) as possible human carcinogens. Long term exposure to $\alpha-\mathrm{HCH}, \beta-$ $\mathrm{HCH}, \Upsilon-\mathrm{HCH}$, or technical grade $\mathrm{HCH}$ has been reported to result in liver cancer. It can also result in blood disorders, dizziness, headache, and possible changes in the levels of sex hormones in the blood (IARC, 2001; ATSD, 2002). They are also irritable and cause nausea when negatively used without caution by applicant.

The detected organochlorines are, delta - BHC (0.111 $\mathrm{mg} / \mathrm{kg})$, Heptachlor epoxide (B) $(0.716 \mathrm{mg} / \mathrm{kg})$, Endosulfan I $(0.059 \mathrm{mg} / \mathrm{kg})$ and Endosulfan II $(1.058 \mathrm{mg} / \mathrm{kg})$. All the detected organochlorines were higher than Codex Recommended MRLs, which could be due to misuse of this organochlorine in the study area, more also the higher values of these organochlorines in the cabbage really shows that consuming cabbage from the study area portend a great health risk. Also, the results shows that the farmers in the study area still use these agrochemicals illegally and also prefer the organochlorines pesticides because they are relatively cheap and very effective (Essumang et al., 2008).

\section{CONCLUSION}

The organochlorine pesticide residues detected in fruit and vegetables samples with their concentrations from the study area were observed to be at alarming levels much higher than the maximum residue limits (MRLs) stipulated by WHO/Codex alimentarius commissions. Majorly, the concentration for Ocs were determined to be $0.007 \mathrm{mg} / \mathrm{kg}$ to $2.303 \mathrm{mg} / \mathrm{kg}$ in this work for lindane in carrot and heptachlor epoxide-B in onions. Generally, the trend of the commonly detected organochlorine in all the samples are heptachlor epoxide $\mathrm{B}>$ endosulfan II $>$ endosulfan $>$ dieldrin $>$ lindane. Therefore, this calls for regular monitoring of pesticide residue and the sensitization of farmers to better pesticide safety practice, especially the need to adhere to recommended routine checking/supervision by relevant agencies so as to minimise the potential health risk associated with these pesticide to consumers.

\section{REFERENCES}

Adeyeye, E.J (2005). Trace metals in soils and plant from Fadama farm in Ekiti State, Nigeria. Bullenting of Chemical Society of Ethopia, 19: 323-324. 
Afful, S., Anim, A.K. and Serfor- Armah.Y.(2010). Spectrum of Organochlorine Pesticide Residues in Fish samples from the Densu Basin. Research Journal of Environment and Earth Sciences 2(3):133-138. ISSN:2041-0492.

Akerblom, M. (1995). Guideline for environmental monitoring of pesticide residues for the SADC SADC/ELMS, Monitoring Techniques Series.

Amoah, P., Diechel, P., Abaidoo, R.C. and Ntow, W.J. (2006).Pesticide and pathogen contamination of vegetables in Ghana's urban market.Arch. Environ. Toxicology 50: 1-6.

Association of Analytical Communities (AOAC) official method 2007.01.

Codex Alimentarius Commission, (2009). Pesticide residues in food: Maximum Residue Limits. Maximum Residue Limits.

Conacher, H.B.S and Mes, J. (1993).Assessment of human exposure to chemical contaminants in Foods.Food Additive Contamination. 10:5-15.

Damalas, A., Christos A. and Ilias, G.E. (2011). Pesticide: exposure, safety issues, and risk Assessment Indicators: International Journal of Environmental Research and Public Health. 2: 77-98

Essumang, D.K., Doboo, D.K., Adokoh, C.K., and Fumador, E.A.(2008). Analysis of some pesticide residues in tomatoes in Ghana. Hum. Ecol. Risk assessment, 14: 796-806.

Fan MA, and Alexeff GV (1999). Public Health Goal for Endrin in Drinking Water. Office of Environment Health and Hazard Assessment, Environmental Protection Agency, California, 5-6.

FAO/WHO (1986) Codex Maximum Limits For Pesticides residues. $2^{\text {nd }}$ ed. Rome, Food and Agriculture Organization of the United Nations Codex Alimentarius Commission (CAC Vol III).

Fernandez - Alba, A,R. and Garcia-Reyes, J,F. (2008). LargeScale mull-residue methods for pesticides and their degradation products in food by advanced LC - MS. TracTrend. Anal.Chem. 27(11):973-990.

Garyd, C. (2008). Analytical Chemistry, Six Edition. WileyIndian Edition. ISBN: 978-81-265-1113-6
IARC (2001). International Agency for Research on Cancer. Organophosphate insecticide and herbicides: Monographs on the Evaluation of Carcinogenic Risks to Humans, vol. 112.

Jobling, S., Reynolds, T., White, R., Parker, M. and Sumpter, J. (1995). Chemical found to mimic human estrogens. Environmental health perseptives. 103:582-587.

Joseph, S. (2001). "RecentAdramen in ThinLayer.Chromalograhy of pesticide". Journal of AOAC international, Vol, 84, No. 4, Pp 993-100.

Lehotay, S.J., Hiemstra M., Van Bodegraven P. and DeKok A. (2007). Validation of a fast and easy method for the determination of more than 200 pesticide residues in Fruits and vegetables using gas and liquid chromatography and mass spectrometric detection J. AOAC Int. $88: 584-595$.

Ogbonnaya, I.C., Abdullahi, M.,Yisa. ,J. and Bala, A. (2014) Assessement of organiichlorinepesticle Residue in soil and water from fadama farming communities in Minna, North Central Nigeria. (AASCIT Journal of Environment. 2(5):4855 .

Sesliing, D.H. and Jackson, R.J. (1994). The effects of prenatal exposure to pesticides: Developmental consequence. Pp 233-248. The John Hopkins University press. Baltimore.

Stephen, W.C., Chung, B. and Benedict, L.S. (2011). Determination of organochlorine pesticide residues in fatty foods. A critical review on the analytical methods and their testing capabilities. Journal of chromatography $A$. 1218(33):5555-5567..

US. Enviromental Protection Agency.(2007). Pesticide regulation(PR) notice 2001- x Draft. Spray and dust drift label statements for pesticide products.

Walter, J.C. (2009). Chlorinated pesticides threats to health and importance of detection".Environmental Medicine. 14(4):347-59.

World Health Organisation (WHO) (1997). Guidelines for dietary intake of pesticide resides. programme of food safety and food aid use, distribution, and reproduction in any medium, provided the original work is cited appropriately. 